\title{
BEM JURÍDICO-PENAL E ESTADO DEMOCRÁTICO DE DIREITO
}

\author{
Gisela França*
}

\begin{abstract}
RESUMO
O presente artigo objetiva analisar a teoria do bem jurídico, notadamente a partir dos princípios norteadores do tema e da Constituição Federal. Assim, destacam-se os reflexos por ela produzidos nas teorias do tipo e do delito, bem como a indissociável relação que possui com o Estado Democrático de Direito em função de ostentar o bem jurídico-penal um caráter limitador do poder punitivo estatal.
\end{abstract}

PALAVRAS-CHAVE: Bem jurídico; Estado Democrático de Direito; Limitação do poder punitivo estatal.

\begin{abstract}
This article aims to analyze the judicial good theory, especially from the guiding principles of the subject and the Constitution. Thus, we highlight the consequences that it produces in the theories of the type and the offense, as well as the inseparable relationship it has with the Democratic State of Law due to bear the character of limiting the state's punitive power.
\end{abstract}

KEYWORDS: Judicial good; Democratic State of Law; Limitation of the state's punitive power.

\section{Introdução}

No presente trabalho, pretendemos pensar a questão do bem jurídico e sua extrema importância para as teorias do tipo e do delito.

Desejamos enfocar a questão sob o prisma conteudístico, constitucional e principiológico, delineando algumas de suas concepções e as abordagens que lhe foram dadas por alguns autores. Considerando a extensão do trabalho e o nível de profundidade que esse nos permite, queremos lançar um olhar sobre o bem-jurídico que nos demonstre sua imprescindibilidade num Estado Democrático de Direito.

Para alcançar esse desiderato, consideramos fundamental que nos detenhamos, sem adentrar em todas as minúcias que perpassam o tema, em algumas considerações gerais acerca do surgimento e modificação do conceito de bem jurídico e sua contextualização teórica, sua relação estreita com os princípios da legalidade, lesividade, intervenção mínima e fragmentariedade, suas funções e em última instância sua

\footnotetext{
* Doutoranda em Direito Penal pela UERJ; Mestre em Direito Penal e Criminologia na Universidade Candido Mendes - UCAM; Coordenadora de Tópicos Especiais I e II na Faculdade de Direito do IBMEC RJ; Professora de Penal da Faculdade de Direito do IBMEC RJ; Professora de Direito Penal e Criminologia da graduação e da pós-graduação da Universidade Estácio de Sá - UNESA.
} 
importância para a legitimação da norma penal e, por via de consequência, do Direito Penal como um todo.

Visamos ainda, demonstrar a impossibilidade de dissociar a noção de delito da noção de bem jurídico, sem atingir-se profundamente o próprio Estado Democrático de Direito. Sem tal convergência a atividade persecutória do Estado poderia tornar-se ilimitada. Adentraríamos então, inevitavelmente, o campo da iniquidade, abrindo espaço para que se punisse pelo simples fato de punir e possibilitando o aparecimento de um Estado Autoritário. Estado este, que no âmbito do Direito Penal poderia dispor a seu "bel prazer" da noção de bem jurídico, não no seu caráter limitador, como abaixo se verá, mas para viabilizar uma atividade punitiva desenfreada que poderia se fundar num direito penal do autor.

\section{Bem Jurídico-Penal: Surgimento, Teorias e Conceito}

Inicialmente gostaríamos de fazer algumas considerações acerca da "idéia de bem", para posteriormente nos lançarmos na tarefa, não menos complexa, de proceder à análise do bem propriamente jurídico-penal.

Conceito amplo e de múltiplos significados, trazemos aqui apenas algumas acepções do que seja o bem.

\footnotetext{
Em geral, tudo que possui valor, preço, dignidade, a qualquer título. Na verdade bem é a palavra tradicional para indicar o que, na linguagem moderna, se chama valor. Um bem é um livro, um cavalo, um alimento, qualquer coisa que se possa vender ou comprar; um bem também é beleza, dignidade ou virtude humana, bem como a ação virtuosa, um comportamento aprovável. (...) A palavra pode ainda num significado mais específico, num recorte, se referir a moralidade, isto é, dos mores, da conduta, dos comportamentos humanos intersubjetivos, designando, assim, o valor específico de tais comportamentos. ${ }^{1}$
}

Do acima exposto se percebe que não há uma superposição do conceito de bem ao de bem jurídico, pois este se constitui num plano próprio e delimitado.

O Direito Penal não procederá à proteção de bens de forma indistinta e aleatória, ou tão pouco procederá a proteção de todos os bens existentes, em decorrência de seu caráter fragmentário. Ao contrário, ficará adstrito à proteção dos bens jurídicos mais relevantes dos ataques mais gravosos que estes estejam suscetíveis de sofrer, consoante a ultima ratio.

\footnotetext{
${ }^{1}$ Cf. Abbagnano, Nicola. Dicionário de Filosofia. São Paulo: Martins Fontes, 1998, p. 107.
} 
É imperioso que haja uma seleção criteriosa de bens, com vistas a estabelecer quais os bens e valores que serão alçados à categoria de bem-jurídico penal, devendo ser tutelados penalmente apenas bens jurídicos fundamentais.

Portanto, o ponto de partida para examinar o tipo ou o delito, não poderá prescindir da necessária perquirição acerca do bem jurídico.

O alicerce para a determinação de uma ação como típica, se assenta na relação de necessidade de lesão ao bem jurídico ${ }^{2}$. Inexistem tipos penais e, pois, delitos dissociados de bens jurídicos.

Embora a dogmática jurídica, via de regra, considere a finalidade protetiva do tipo como o aspecto preponderante, dessa forma alocando o bem jurídico na condição de pressuposto do tipo, como objeto de proteção ${ }^{3}$, Juarez Tavares assevera que em verdade não é possível considerar como pressuposto do tipo a proteção de bem jurídico, porque tal proteção não possuiria conteúdo real. Isto porque não se pode aquilatar se a simples formulação típica de uma conduta como penalmente proibida (ou seja, a inserção de um bem jurídico na esfera penal) proteja de fato o bem jurídico. Essa menção protetiva ao bem jurídico estaria circunscrita ao âmbito apenas formal, servindo de mera referência. Continua o autor, afirmando que se considerarmos a proteção ao bem jurídico como pressuposto do tipo estaremos ancorados numa concepção meramente sistêmica, em que o tipo se constituiria num instrumento de manutenção e reprodução da norma, olvidando-se a sua dimensão de garantia. ${ }^{4}$

Ao pensarmos a norma penal desatrelada de um viés autoritário, meramente imperativo, mas somente como um instrumento de garantia individual, ela poderá ser percebida na sua dimensão democrática, rompendo com a idéia do tipo como tendo a função última de proteger o bem jurídico. ${ }^{5}$

Trataremos do surgimento e das modificações do conceito de bem jurídico, em linhas bem gerais, para não extrapolar o objetivo do trabalho e devido à complexidade teórica que envolve o tema.

A teorização acerca do conceito de bem jurídico sofreu um incremento a partir da primeira metade do século XIX, momento em que se iniciam as refutações da concepção clássica (de matriz iluminista), que vigorava anteriormente, do crime como sendo uma ofensa a um direito subjetivo, passando a ser concebido como uma ofensa a bens. ${ }^{6}$ Essa modificação

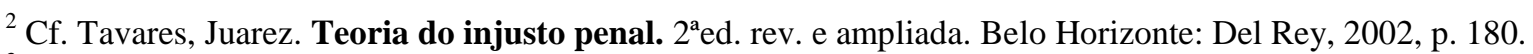

${ }^{3}$ Cf., nesse sentido, Fragoso. Lições de Direito Penal. Rio de Janeiro: Forense, 2003, p. 225.

${ }^{4}$ Cf. Tavares, Juarez. Op. cit., p. 180.

${ }^{5}$ Cf. Idem, Ibidem, p. 181.

${ }^{6}$ Cf. Batista, Nilo. Introdução Crítica ao Direito Penal. Rio de Janeiro: Revan, 1999, p. 94.
} 
conceitual inicia-se em consonância com os ditames do movimento Iluminista, em que a questão punitiva despoja-se de conotações ético-religiosas, assentando-se o delito na violação do Contrato Social e tendo a pena um sentido preventivo. ${ }^{7}$

Johann M.F.Birnbaum é considerado o responsável pela elaboração do conceito de bem jurídico-penal que rompe com essa visão iluminista, alicerçada na idéia de Anselm von Feuerbach. Segundo este o delito seria uma lesão a direito subjetivo, subordinado assim a um princípio material - a preservação da liberdade individual. Feuerbach esboçava um avanço, pois era uma forma de delimitação da incriminação e do arbítrio estatal, uma vez que o delito deixa de ser visto como uma lesão de um dever para com o Estado. Diferentemente, Birnbaum passa a considerar o delito como sendo uma lesão a bens jurídicos. ${ }^{8}$

Assim, pode-se afirmar que Birnbaum foi responsável por substituir a idéia de direito subjetivo pela concepção de bem jurídico penal e observar a imprescindibilidade para a tutela penal de um bem diretamente conectado no mundo do ser ou da realidade relevante para a pessoa ou a coletividade e que pudesse ser lesionado pela conduta criminosa.

Karl Binding, um dos expoentes de uma concepção positivista ${ }^{9}$ do bem jurídico, o considera um pressuposto formal da norma incriminadora, consistindo o delito na lesão a um direito subjetivo do Estado. Estabelece uma relação entre as normas e os bens jurídicos, uma vez que as agressões aos direitos subjetivos somente se produziriam mediante a agressão aos bens jurídicos e seria inconcebível sem estes. ${ }^{10}$ Tem-se uma identidade entre o bem jurídico, o sentido e os fins da norma penal. O bem jurídico é concebido como um estado valorado pelo Legislador $^{11}$, sendo a decisão estatal (legislativa) de proteger determinado "valor" um dado de suma importância. A norma seria a criadora do bem jurídico.

A "opacidade" da idéia de bem-jurídico adveio do pensamento de Hegel, principal expoente do idealismo filosófico alemão, que inaugurou um grande processo de abstração e

\footnotetext{
${ }^{7}$ Cf. Prado, Luiz Regis. Bem jurídico-penal e Constituição. São Paulo: Editora Revista dos Tribunais, 1997, p. 27.

${ }^{8}$ Cf. Tavares, Juarez. Op. cit., p. 182-3.

${ }^{9}$ Juarez Tavares, $O p$. cit., p. 187. O autor apresenta como traços próprios da visão positivista "considerar que toda norma incriminadora deve possuir um antecedente causal e tal antecedente poderá ser a vontade do Estado ou da autoridade acorde com o positivismo jurídico propriamente dito ou condições de vida, como no positivismo sociológico. A noção de bem jurídico irá variar conforme essas duas vertentes. No positivismo jurídico, somente a lei expressa os objetivos jurídicos, porque encerra a vontade declarada do estado, logo o bem jurídico se reduz a um elemento da própria norma, que tanto pode ser sua finalidade quanto a ratio do sistema. De acordo com o posicionamento sociológico, derivado, por desdobramento, da escola histórica, o direito tem sua fonte não apenas na lei, mas principalmente no costume, ou no espírito do povo, como sintetizador de uma vontade geral, ao estilo contratualista ou organicista".

${ }^{10}$ Cf. Prado, Luiz Regis. Op. cit., p. 31.

${ }^{11}$ Cf. Bitencourt, Cezar Roberto. Manual de direito penal: parte geral, volume 1. São Paulo: Saraiva, 2000, p. 198.
} 
idealização de seu significado, sendo para os hegelianos o único objeto do delito a vontade geral com a qual o Estado seria o detentor exclusivo do bem-jurídico.

Franz von Liszt, também vinculado à tradição positivista, considera o bem jurídico como o ponto central da teoria do delito e como sendo o interesse juridicamente protegido, mas independente - para a sua existência enquanto bem - da vontade do Legislador. O interesse do qual se origina o bem jurídico é anterior à norma, se situa num momento precedente, sendo esperado que a norma o abarque devido a sua essencialidade dentre os interesses humanos. $\mathrm{O}$ bem jurídico existe enquanto fenômeno, independentemente e desvinculado da norma penal, sendo uma criação da experiência humana e de suma relevância para o indivíduo enquanto singularidade e para a coletividade. ${ }^{12} \mathrm{O}$ seu caráter positivista fica por conta da falta de critérios que possibilitem a crítica ou a limitação da escolha de um determinado bem pelo Legislador como objeto de tutela, ficando assim, malgrado a afirmação de anterioridade do bem à criação da norma, tida por justificada qualquer escolha feita pelo Legislador. $^{13}$

No início do século XX, surge a concepção neokantista do bem jurídico, resultado de uma leitura renovada da obra de Immanuel Kant. Percebe-se a substituição da noção de indivíduo (sujeito) pela noção de totalidade, que embora apresentada como fundada em um suposto juízo neutro e normativo puro é impregnada de um inegável traço autoritário. Ocorre a superação da noção material de bem pela noção de valor, não de um valor individual, mas de um hipotético valor cultural, expresso nas proibições da norma.

A descrição legal (denotativa de um complexo cultural) expressa um valor ao qual é agora equiparada a noção de bem jurídico. O bem jurídico é derivado da própria elaboração e da finalidade da norma. Essa concepção vincula bem jurídico, norma de cultura e norma jurídica. É nesse sentido a obra de Mezger, em especial seu Tratado de Direito Penal. ${ }^{14}$

A tradição neokantista daria, contudo, frutos bem diversos. Max Ernst Mayer veria na relação entre bem jurídico, valor e cultura o delineamento de um substrato pré-jurídico dos processos legislativos, a apontar para o esboço de um caráter ontológico da noção de bem jurídico, ao contrário do esvaziamento que lhe imprimiu Mezger, verdadeiro pensador neopositivista. $^{15}$

\footnotetext{
${ }^{12}$ Cf. Tavares, Juarez. Op. cit., p. 181-2 e 188. Prado, Luiz Regis. Op. cit., p. 32.

${ }^{13}$ Cf. Tavares, Juarez. Op.cit., p. 188-9. O autor aponta ser esse o teor da crítica que Hassemer dirige ao pensamento de Von Liszt.

${ }^{14}$ Idem, Ibidem. Op. cit., p. 189.

${ }^{15}$ Idem, Ibidem. Op. cit., p.190-1.
} 
Welzel, dentro de uma visão ontológica, trabalha com valores ético-sociais. O nascedouro das determinações ou proibições jurídicas repousaria sobre uma perquirição da formação da consciência ética individual, emanada de deveres incondicionais transcendentes, ao estilo kantiano do imperativo categórico. O indivíduo busca, porém, dar sentido a tais imperativos, incorporados à consciência humana de cada um como um verdadeiro projeto sensível, modelo de ação ${ }^{16}$, ou seja, à medida que tais comandos são sentidos pelo indivíduo como determinações e esquematizados em modelos de ação, servirão de parâmetro para suas condutas.

Welzel considera que há um liame subjetivo entre o dever e a pessoa, uma vez que o respeito à norma, dependerá do imperativo ético e da disposição individual para obedecê-lo. O imperativo categórico é o fundamento da ação e orienta um projeto social de proteção dos pressupostos elementares de sua existência, tratados como valores ético-sociais. ${ }^{17}$ Welzel, com sua formulação, relega o bem jurídico a um segundo plano.

\footnotetext{
A proteção de valores ético-sociais nada mais é do que a incriminação da antisociabilidade, daí não ser incoerente que seus adeptos [dentre eles Welzel] venham a conceituar o bem jurídico como um estado social, ou seja, uma determinada ordem, que se impõe como bem vital do indivíduo e da comunidade. ${ }^{18}$
}

Já consoante os preceitos do funcionalismo, pugnando pela ordem e manutenção do sistema, podemos diferir e alinhar três grupos de concepções ${ }^{19}$ a respeito do bem jurídico.

O primeiro grupo de concepções parte do pressuposto de que a norma penal é um instrumento de controle social que deverá servir para garantir a reprodução e estabilidade do sistema. Consideram seus adeptos que existem alguns pressupostos existenciais que de acordo com a sua utilidade se fazem necessários para a manutenção do sistema, por não se poder prescindir de certas necessidades humanas de realização pessoal para que se atinja o escopo colimado de manutenção do sistema.

Em decorrência da norma penal possuir como finalidade o controle social, faz-se necessário a sua comunicação constante a todos, acerca das imposições e proibições que deverão ser aceitas e atendidas pelos membros da comunidade para evitar as perturbações do sistema. Tais perturbações do sistema geram um processo de reação exeqüível através da imposição de uma sanção, que se legitima em decorrência de uma decisão dogmaticamente fundamentada. Assim se garantiria a reprodução do sistema e sua estabilidade.

\footnotetext{
${ }^{16}$ Idem, Ibidem, p. 191.

${ }^{17}$ Idem, Ibidem, p. 192.

${ }^{18}$ Idem, Ibidem, p. 193.

${ }^{19}$ Cf. Tavares, Juarez. Op. cit., p. 195.
} 
Muñoz Conde pode ser inserido nesse grupo, na medida em que trabalha as exigências de uma realidade social e as idéias funcionais. Logo, os conflitos geram a necessidade de intervenção sob o pressuposto de utilidade, o que não significa desatender à realidade social e existencial do homem, mas apenas limitar o que deve ou não ser protegido. A proximidade à concepção funcional não afasta Muñoz Conde de uma visão crítica sobre o bem jurídico, quando, por exemplo, ele afasta desse âmbito simples interesses de classe ou de políticas estatais. $^{20}$

Um segundo grupo de concepções, ao qual se filia o pensamento de Jakobs, partindo do pressuposto de que as normas penais devem assegurar uma expectativa de conduta adequada, o bem jurídico passa a se identificar e aproximar do sentido de validade fática da norma.

O terceiro grupo, possuindo Roxin, como um de seus representantes, pretende inicialmente revigorar a noção de bem jurídico. Partindo de um arcabouço constitucional como sendo capaz de restringir o poder punitivo do Estado, conclui que o bem jurídico, compatível com seu caráter funcionalista, deve possuir como finalidade a manutenção do sistema.

Juarez Tavares alinha tais grupos de concepções e os denomina respectivamente: modelo funcional estrutural, modelo funcional próprio e modelo funcional impróprio.

Vale frisar, que alguns membros da vertente funcionalista consideram o bem jurídico algo de somenos importância, considerando que a finalidade do direito e da norma penal, em última ratio, é pugnar pela estabilidade do sistema, não sendo necessária a noção de bem jurídico, uma vez que esta busca da estabilidade do sistema justificaria qualquer conteúdo normativo, abrindo um leque variado de possíveis arbitrariedades. ${ }^{21}$

\section{Funções do bem jurídico}

O bem jurídico possui inúmeras funções. Traremos à colação aquelas que entendemos mais representativas de sua importância.

\footnotetext{
${ }^{20}$ Idem, Ibidem, p. 196.

${ }^{21}$ Cf. Amelung, Knut apud Tavares, Juarez. Op. cit., p. 196.
} 


\section{A) Função de garantia ou limitadora}

O princípio da lesividade tem como uma de suas funções a de proibir a incriminação de condutas que não afetem um bem jurídico ${ }^{22}$. Pelo princípio da legalidade, para que haja delito há que se ter um bem jurídico lesado, protegido em lei na seara jurídico-penal. Sendo o Direito Penal fragmentário, não protege todos os bens jurídicos de todos os tipos de violação, mas apenas os bens jurídicos mais importantes contra as formas mais graves de agressão.

O legislador está desde logo, adstrito a tipificar apenas as condutas mais graves que lesionem ou coloquem em perigo, os bens jurídicos considerados mais importantes.

Percebemos nessa função limitadora, na medida em que impede o poder punitivo estatal de proceder a uma seletividade aleatória, um matiz político-criminal ${ }^{23}$, uma vez que procedendo restritivamente quanto ao momento de produção legislativa de tipos penais, simboliza uma garantia do indivíduo.

A função em tela condiciona a validade da norma e subordina a sua eficácia à questão de ter havido efetiva lesão ou ameaça de lesão a um bem jurídico.

O bem jurídico delimita a norma e sua elaboração. Assim, trata-se de uma ferramenta de limitação do poder punitivo estatal, evitando a inflação e a expansão desse poder.

\section{B) Função exegética}

Todo delito há que necessariamente ameaçar ou lesionar um bem jurídico. Desse modo este é um elemento basilar do preceito. Para que se possa interpretar a lei penal, tem-se que partir da premissa de que ela protege um bem jurídico. Então, para compreendê-la, teremos que ser remetidos à noção de bem jurídico. Temos nele "um critério de interpretação dos tipos penais, que condiciona seu sentido e seu alcance à finalidade de proteção de certo bem jurídico, não sendo possível interpretar, nem por via de conseqüência conhecer, a lei penal, sem lançar mão da idéia de bem jurídico"24.

\footnotetext{
${ }^{22}$ Cf. Batista, Nilo. Op.cit., p. 94.

${ }^{23}$ Cf. Prado, Luiz Regis. Op. cit., p. 48.

${ }^{24}$ Cf. Navarrete, Polaino apud Prado, Luiz Regis. Op. cit., p. 48.
} 


\section{C) Função individualizadora}

É a função de servir como um dos critérios de dosimetria da pena, no momento concreto de sua fixação, na medida em que se levará em conta para tanto a gravidade da lesão ao bem jurídico. ${ }^{25}$

\section{D) Função sistemático-classificatória}

O bem jurídico funciona como um critério de agrupamento de crimes utilizado na parte especial do nosso código penal ${ }^{26}$, uma vez que tais crimes são agrupados em determinadas categorias conforme o bem jurídico protegido, o que propicia a criação de um sistema. Funciona como um elemento classificatório determinador do agrupamento de tipos penais. Por certo, não se trata de questão a ser equiparada na sua importância aos demais papéis que assume o bem jurídico para o Direito Penal, embora se vislumbre também aqui uma de suas utilidades.

\section{E) Função Crítica}

Esta função manifesta-se na medida em que, a partir da identificação do bem jurídico, se pode indagar o porquê da opção legislativa ter se dado na escolha daquele bem jurídico e não de outros. Perquirindo dessa forma acerca das finalidades do legislador, se pode aceder a uma crítica do Direito Penal como um todo. ${ }^{27}$

Segundo Juarez Cirino dos Santos, atualmente juristas e criminólogos críticos sugerem que o conceito de bem-jurídico deve se circunscrever aos direitos e garantias individuais do ser humano, excluindo-se desta feita a criminalização da vontade de poder, de papéis sistêmicos, do risco abstrato ou de interesses difusos. Tal posição, prossegue, Juarez Cirino, reafirma os princípios penais alicerçados num direito penal do fato, com a necessária lesão ao

\footnotetext{
${ }^{25}$ Cf. Prado, Luiz Regis. Op. cit., p. 49.

${ }^{26}$ Cf. Prado, Luiz Regis. Op. cit., p. 49. Batista, Nilo. Op. cit., p. 96.

${ }^{27}$ Cf. Batista, Nilo. Op. cit., p. 97.
} 
bem-jurídico e a culpabilidade enquanto fundamento e medida da pena, logo limitadora do jus puniendi estatal. $^{28}$

\section{Princípios limitadores do poder punitivo estatal e bem jurídico-penal}

Sabe-se que "bem" é tudo aquilo que pode satisfazer as necessidades humanas e todo valor reconhecido pelo Direito torna-se um bem jurídico.

Bem, para Francisco de Assis Toledo, em sentido muito amplo, é tudo o que se apresenta como digno, útil, necessário e valioso.

E a proteção aos bens jurídicos é norteada pelos princípios fundamentais de direito penal, dentre os quais selecionamos alguns para mencionar:

\section{a) Princípio da Legalidade ou da Reserva Legal}

O Princípio da Legalidade está preceituado na Constituição Federal de 1988, art. $5^{\circ}$, XXXIX e no Código Penal no art. $1^{\circ}$, que preceitua: Não há crime sem lei anterior que o defina; não há pena sem prévia cominação legal.

O aparecimento do princípio da legalidade ocorreu com o advento da Magna Carta (século XIII), em que barões ingleses impunham suas vontades ao rei João. O princípio se cristalizou com o Iluminismo através das formulações de Beccaria (1764). Mas o principal defensor deste princípio foi Feuerbach que nos trouxe, no início do século XIX, a sistematização, num brocardo latino que define o princípio da legalidade: nullum crimen nulla poena sine lege.

Cumpre ressaltar que no Brasil o princípio da legalidade existe desde a Constituição de 1824, sem nunca ser ter sido formalmente suprimido.

Para que o Direito Penal possa atuar sobre a esfera da individualidade é necessário que existam proibições casuísticas e que as mesmas tenham como escopo a proteção de um bemjurídico relevante. Ou seja, caso a caso o legislador penal deverá dizer o que é proibido, havendo evidentemente em algumas hipóteses o recurso a interpretação analógica de resultado extensivo.

\footnotetext{
${ }^{28}$ Cf. SANTOS, Juarez Cirino dos. Direito Penal: parte geral. Curitiba: ICPC; Lumen Juris, 2007, p. 16.
} 
Pelo princípio da Legalidade, a elaboração das normas penais incriminadoras é função exclusiva da lei, isto é, nenhum fato pode ser considerado crime e nenhuma pena criminal pode ser aplicada sem que antes da ocorrência desse fato exista uma lei definindo-o como crime e cominando-lhe a sanção correspondente. A lei deve definir com precisão e de forma cristalina a conduta proibida.

O princípio da Legalidade assegura a possibilidade de um prévio conhecimento dos crimes e das penas, assim como também garante que o cidadão não seja submetido à coerção penal distinta daquela disposta em lei.

O Princípio da Legalidade é imprescindível para o Direito Penal Democrático. É a maior garantia que o indivíduo possui contra a intervenção do Estado sobre a sua esfera de privacidade. Significa uma limitação do poder punitivo estatal sobre os indivíduos.

Somente Lei em sentido estrito ou formal (manifestação da vontade coletiva expressa através de órgãos constitucionais - Poder Legislativo) poderá definir crimes e estabelecer penas, sendo assim, do rol do artigo 59 da CRFB/88, somente as três primeiras espécies normativas são aptas para a definição de crimes e a cominação de penas, consoante o art. $62 \S$ $1^{\circ}$, inciso $\mathrm{I}$, alínea $\mathrm{B}$, da $\mathrm{CRFB} / 88$. Logo, para efeitos penais, o processo legislativo compreende a elaboração de Emendas à Constituição; Leis Complementares e de Leis Ordinárias. Não se admite a previsão de infrações penais, a cominação de penas e medidas de segurança por meio de medidas provisórias, de leis delegadas, de decretos legislativos e de resoluções.

\section{b) Princípio da Intervenção Mínima}

Procurando restringir ou impedir o arbítrio do Legislador, no sentido de evitar a definição desnecessária de crimes e a imposição de penas injustas, desumanas ou cruéis, a criação de tipos delituosos deverá obedecer à imprescindibilidade, só devendo intervir o Estado, por intermédio do Direito Penal, quando os outros ramos do Direito não conseguirem prevenir a conduta ilícita.

O princípio da intervenção mínima, também conhecido como ultima ratio, orienta e limita o poder incriminador do Estado, preconizando que a criminalização de uma conduta só se legitima se constituir meio necessário para a proteção de determinado bem jurídico.

Se outras formas de sanção ou outros meios de controle social se revelarem suficientes para a tutela desse bem jurídico, a sua criminalização é inadequada e não recomendável. 
Em síntese, antes de se recorrer ao Direito Penal deve-se esgotar todos os meios extrapenais de controle social.

De acordo com o referido princípio o Direito Penal deve ser a última forma de Intervenção do Estado, só devendo ser utilizado, quando outras formas de Intervenção menos severas tiverem falhado.

O Direito Penal mínimo é aquele que tem que ser aplicado na medida certa, somente o que é necessário.

O princípio da intervenção mínima deve ser analisado sob dois enfoques diferentes, a saber:

a) deve ser entendido como um princípio de análise abstrata, que serve de orientação ao legislador quando da criação ou da revogação das figuras típicas;

b) evidencia a chamada natureza subsidiária do Direito Penal, devendo ser ele considerado como a ultima ratio de intervenção do Estado.

Na primeira vertente, em um enfoque minimalista, o escopo do Direito Penal é proteger os bens jurídicos mais importantes e necessários ao convívio em sociedade. Partindo dessa visão, somente os bens de maior relevo é que irão merecer a atenção do legislador penal que, a fim de protegê-los, deverá criar os tipos penais incriminadores, proibindo ou determinando a prática de comportamentos sob a ameaça de uma sanção.

Em sua segunda vertente, o princípio da intervenção mínima deixa entrever a necessidade de o Direito Penal ser aplicado de forma subsidiária, tendo em vista a drasticidade de sua intervenção, permitindo, assim, alicerçado no princípio da dignidade da pessoa humana, que outros ramos do ordenamento jurídico, com primazia, procurem fazer a proteção dos bens jurídicos, somente sendo necessária a interferência do Direito Penal quando os outros ramos demonstrarem que são ineficazes ou insuficientes na sua proteção aos bens jurídicos.

Segundo Claus Roxin, o Direito Penal é o remédio sancionador extremo. Não sendo legítimo criar tipos penais para a proteção de bens jurídicos sendo esses descritos através de conceitos meramente abstratos, ou seja, sem uma conotação real e concreta ${ }^{29}$.

\section{c) Princípio da Fragmentariedade}

\footnotetext{
${ }^{29}$ Roxin, Claus. Estudos de direito penal. Rio de Janeiro: Renovar, 2006, p.50.
} 
Binding, em seu Tratado de Direito Penal Alemão de 1896, foi o primeiro doutrinador a registrar o princípio da fragmentariedade.

A fragmentariedade do Direito Penal é corolário dos princípios da intervenção mínima e da reserva legal.

Nem todas as ações que lesionam bens jurídicos são proibidas pelo Direito Penal, como nem todos os bens jurídicos são por ele protegidos. O Direito Penal limita-se a castigar as ações mais graves praticadas contra os bens jurídicos mais importantes, decorrendo daí o caráter fragmentário.

O Direito Penal não constitui um sistema exaustivo de proteção de bens jurídicos, de sorte a abranger todos os bens que constituem o universo de bens do indivíduo.

Em suma, caráter fragmentário do Direito Penal significa que o Direito Penal não deve sancionar todas as condutas lesivas dos bens jurídicos, mas tão somente aquelas condutas mais graves e mais perigosas praticadas contra os bens mais relevantes.

\section{Conclusão.}

$\mathrm{O}$ que transforma um bem qualquer existente em um bem jurídico penal é uma escolha legislativa perpassada por escolhas políticas que se inserem num contexto social, econômico e histórico de uma determinada sociedade numa dada época.

Numa sociedade de classes, os bens jurídicos hão de expressar, de modo mais ou menos explícito, porém inevitavelmente, os interesses da classe dominante, e o sentido geral de sua seleção será o de garantir a reprodução das relações de dominação vigentes, muito especialmente das relações econômicas estruturais. ${ }^{30}$

O bem jurídico, na concepção democrática proposta por Luiz Regis Prado, terá seu ponto de partida no conceito de pessoa e o Direito Penal se verá subordinado aos preceitos constitucionais e aos direitos fundamentais da pessoa. Se configurando desta forma em um obstáculo a incriminação de condutas. Para o autor, a noção de bem jurídico estará associada à idéia de que o estado é que serve ao indivíduo e que este tem de garantir a liberdade e dignidade humanas. O Direito Constitucional funcionará como um norte de hierarquia superior que imporá os limites ao direito de punir, limites estes que deverão se compatibilizar com as garantias do Estado Democrático de Direito e estar previamente delineados na

\footnotetext{
${ }^{30}$ Batista, Nilo. Op. cit., p. 96.
} 
Constituição. O Legislador terá que definir os bens jurídicos partindo dos ditames e limites impostos na Constituição e dos valores nela consagrados. Terá na norma constitucional o substrato primeiro para possibilitar ou não uma incriminação de conduta.

A existência do delito e sua previsão jurídico-normativa repousaria na compatibilidade da escolha do bem jurídico tutelado com seu tratamento constitucional, escolha esta que seria, nesse diapasão reflexivo, um dos valores supremos de determinada coletividade, entendida esta como realizadora e abarcadora de singularidades e particularidades humanas.

“A conceituação material de bem jurídico deve implicar no reconhecimento de que o legislador eleva à categoria de bem jurídico o que já na realidade social se apresenta como um valor." 31

Regis Prado considera como bens suscetíveis de proteção penal os direitos constitucionais do cidadão, os valores objetivamente tutelados e outros que se insiram no contexto de garantia do Estado Democrático de Direito.

A lesão a um bem jurídico para ser "guindada" à condição de lesão a um bem jurídico-penal deverá se revestir de uma gravidade e de uma danosidade social de tal monta, que não lhe seja passível de tutela eficaz e efetiva pelos demais ramos do direito.

O bem jurídico na qualidade de valor e, conseqüentemente, inserido no amplo aspecto da finalidade da ordem jurídica cumpre a função de proteção, não dele próprio, senão da pessoa humana, que é o objeto final de proteção da ordem jurídica. Isto significa que o bem jurídico só vale na medida em que se insira como objeto referencial de proteção da pessoa, pois só nesta condição é que se insere na norma como um valor. ${ }^{32}$

De tudo que foi exposto acima, se depreende que a característica fundamental do bem jurídico é a de delimitador da norma penal e de garantia do indivíduo frente ao Estado.

A existência do bem jurídico não deve ser vista como propiciadora da incriminação, mas ao contrário como um delimitador que obstaculize "inflações penais", próprias de políticas autoritárias em que o bem jurídico se vê esvaziado de real significado e materialidade e comporta tudo aquilo que o estado despoticamente considera necessário para realizar seus fins, cingindo-se assim, às obscuras "Razões de Estado".

Pugnamos pela manutenção do conceito de bem jurídico na seara penal e compreendemos ser sua noção de suma importância. Tememos uma substituição da idéia de bem jurídico pela de estabilidade normativa ou de pura manutenção do sistema.

\footnotetext{
${ }^{31}$ Prado, Luiz Regis. Op. cit., p. 76.

32 Tavares, Juarez. Op. cit., p. 199.
} 
Uma sociedade que se pretenda democrática terá que abrigar um rol de valores, bens, diretrizes, que dada sua importância social e visto como mecanismo de proteção dos direitos humanos numa dimensão individual-social, seja resguardado de agressões violentas em âmbito penal e ponham os indivíduos à salvo de tais agressões e dos abusos do Poder Estatal.

O objetivo do Direito Penal, a despeito da proteção dos bens jurídicos socialmente mais relevantes, terá que se pautar pela permissão da intromissão Estatal na esfera da liberdade humana somente em última instância e no estritamente necessário.

\section{REFERÊNCIAS:}

BARATTA, Alessandro. Criminologia Crítica e Crítica do Direito Penal: Introdução à Sociologia do Direito Penal, Tradução Juarez Cirino dos Santos, Rio de Janeiro: Editora Revan: Instituto Carioca de Criminologia, 2002.

BATISTA, Nilo. Introdução Crítica ao Direito Penal Brasileiro. Rio de Janeiro: Revan, 1999.

BECCARIA, Cesare. Dos Delitos e das Penas. $2^{\text {a }}$ ed., São Paulo: Editora Revista dos Tribunais, 1999.

BETIOL, Giuseppe. O Problema Penal. Campinas: LZM, 2003.

BITENCOURT, Cezar Roberto. Manual de Direito Penal: parte geral, volume 1. São Paulo: Saraiva, 2000.

DIAS, Jorge de Figueiredo. Direito Penal: parte geral: tomo I: questões fundamentais. Portugal: Coimbra Editora, 2007.

FIANDACCA, Giovanni; MUSCO, Enzo. Diritto Penale, parte generale, Bologna: Zanicheli, 1997.

FIANDACA, Giovanni. Il bene giuridico come problema teorico e come criterio di politica criminale in RIDPP., 1982.

FRAGOSO, Heleno Cláudio. Lições de Direito Penal: parte geral. Rio de Janeiro: Editora Forense, 2003. 
GARCÍA - Pablos de Molina, Antonio e GOMES, Luiz Flávio. Criminologia: Introdução a seus fundamentos teóricos. São Paulo: Editora Revista dos Tribunais, 2002.

HASSEMER, Winfried. Introdução aos fundamentos do Direito Penal. Porto Alegre: Sergio Antonio Fabris, 2005.

LUISI, Luiz. Os Princípios Constitucionais Penais. Porto Alegre: Sergio Antonio Fabris, 2003.

MUÑOZ Conde, Francisco. Teoria geral do delito. Porto Alegre: Fabris, 1998.

FERRAJOLI, Luigi. Direito e Razão -Teoria do Garantismo Penal. São Paulo: RT, 2002.

LISTZ, Franz Von. Tratado de Direito Penal. Campinas: Russell, 2003.

PRADO, Luiz Regis. Bem jurídico-penal e Constituição. São Paulo: Editora Revista dos Tribunais, 1997.

ROXIN, Claus. Estudos de Direito Penal. Rio de Janeiro: Renovar, 2006, p.50.

SANTOS, Juarez Cirino dos. Direito Penal: parte geral. Curitiba: ICPC; Lumen Juris, 2007. A Moderna Teoria do Fato Punível. Rio de Janeiro: Revan, 2002.

SIMAZ, Leonel Alexis (Org.).Temas de Derecho Penal Argentino. Buenos Aires: La Ley, 2006.

TAVARES, Juarez. Teoria do Injusto Penal. Belo Horizonte: Del Rey, 2002.

TAVARES, Juarez. Direito penal da negligência, $2^{\text {a }}$ edição, Rio de Janeiro: Lumen Juris, 2003.

TOLEDO, Francisco de Assis. Princípios Básicos de Direito Penal. São Paulo: Saraiva, 2002. 
WELZEL, Hans. Direito Penal. Campinas: Romana, 2003.

ZAFFARONI, Eugênio Raúl. Manual de Direito Penal Brasileiro: Parte geral. São Paulo: Editora Revista dos Tribunais, 2001.

ZAFFARONI, E. Raul/ Batista, Nilo. Tratado de direito penal brasileiro, volumes I e II, Rio de Janeiro: Revan, 2009. 